\title{
Managing healthcare technology in quality management framework
}

\author{
Prasanta Kumar Dey* \\ Aston Business School, \\ Aston University, Aston Triangle, \\ Birmingham B4 7ET, UK \\ E-mail: p.k.dey@aston.ac.uk \\ ${ }^{*}$ Corresponding author
}

\section{Seetharaman Hariharan}

Anaesthesia and Intensive Care,

The University of the West Indies,

St. Augustine, Trinidad, West Indies

E-mail: uwi.hariharan@gmail.com

\section{William Ho}

Aston Business School,

Aston University,

Aston Triangle, Birmingham B4 7ET, UK

E-mail: w.ho@aston.ac.uk

\begin{abstract}
Healthcare services available these days deploy high technology to satisfy both internal and external customers by continuously improving various quality parameters. Quality improvement in healthcare services is a complex and multidimensional task. Although various quality management tools are routinely deployed for identifying quality issues in healthcare delivery, there is absence of an integrated approach, which can identify and analyse issues, provide solutions to resolve those issues and develop a project management framework to implement and evaluate those solutions. This study introduces an integrated and uniform quality management framework for healthcare services. This study uses the Logical Framework Analysis (LFA) to improve the performance of healthcare services. LFA has three major steps - problem identification, solution derivation and formation of a planning matrix for implementation and evaluation. LFA has been applied in a case study environment to three acute healthcare services (Operating Room (OR) utilisation, Accident and Emergency (A\&E) and intensive care) in order to demonstrate its effectiveness.
\end{abstract}

Keywords: healthcare services; technology management; quality management; Logical Framework Analysis; LFA.

Reference to this paper should be made as follows: Dey, P.K., Hariharan, S. and Ho, W. (2007) 'Managing healthcare technology in quality management framework', Int. J. Technology Management, Vol. 40, Nos. 1/2/3, pp.45-68. 
Biographical notes: Prasanta Kumar Dey is a Senior Lecturer in Aston Business School, Birmingham, UK. He specialises in operations and information management. Prior to joining Aston, he worked in Indian Oil Corporation Limited (a fortune five hundred company), India as a project executive for 13 years and worked in various oil refining and pipelines transportation projects. Subsequently, he directed and lectured in a graduate project management programme in the University of the West Indies, Barbados for five years. He holds a Bachelor degrees in Mechanical Engineering, Master's in Industrial Engineering and Management and a $\mathrm{PhD}$ in Production Engineering. He has published extensively in the international refereed journals like International Journal of Project Management, International Journal of Production Economic, International Journal of Operations and Production Management, IEEE Transactions on Engineering Management, International Journal of Technology Management, Impact Assessment and Project Appraisal and Environmental Impact review. His current research interest includes total quality management, supply chain management and project management in both manufacturing and service industries.

Seetharaman Hariharan is a Consultant in The Eric Williams Medical Sciences Complex (ESMSC) in Trinidad and Lecturer in the University of the West Indies, Trinidad. He specialises in critical care medicine and worked in India and Barbados prior to joining in the ESMSC. His current research interest is quality management in the intensive care units of hospital.

William Ho is a Lecturer in the Aston Business School, The Aston University. $\mathrm{He}$ received a BE and a PhD from the Department of Industrial and Systems Engineering, The Hong Kong Polytechnic University. His research areas include the applications of operations management and operations research techniques in the printed circuit board assembly, supply chain management/ logistics and higher education management processes.

\section{Introduction}

Healthcare is the fastest growing service in both the developed and developing countries. With the explosive development of knowledge, technology and globalisation there is now an increasing requirement of high-technology medical care. Every country is striving hard to cope with this increasing need of healthcare facilities in terms of both human and material resources (Feeney and Zairi, 1996). However, it is important that these facilities are available; they perform to the required standards so as to satisfy both healthcare personnel and patients. Like any other industry, operations in healthcare industry are considered as a series of process and superior performance of these process is essential in order to remain competitive.

Continuous Quality Improvement (CQI) concept has been deployed in large-scale manufacturing industry (Lange Ros and Boer, 2001) as well as in small- and medium-sized industry (Coughlan et al., 2001). CQI has also been applied in healthcare by many researchers in the Emergency Department (Fernandes and Christenson, 1995, 1996; Re and Krousel-Wood, 1991). Data-Attitude-Tools (D*A*T), Deming's PDCA cycle, Utilisation Review and Management have been suggested for quality improvement in healthcare services by researchers (Berwick, 1998; Van Matre, 1992). However, many of these are general guidelines and do not specifically address the unique problems of specific services in the hospital-based healthcare system. Moreover, planning and 
implementing the improvement projects is the most challenging task, which was not discussed by any of the above studies. In the hospital-based healthcare practices, there are uniform and global approaches towards identifying deficiencies of specific service and planning strategies to mitigate those deficiencies in order to achieve superior performance (Lurie et al., 2002). Most of the healthcare units use a peer-review process to identify issues and concerns of improved performance (Snelson, 1992). The Joint Commission on Accrediting Healthcare Organisations proposed a '10-step monitoring and evaluation process' for improving quality of healthcare services (Evan and Lindsay, 2002). Although this identifies problems and concerns of specific unit, it does not provide a framework of strategies for corrections and improvement. Chen et al. (2004) reported issues of implementing total quality management projects in healthcare service in Taiwan.

Quality in healthcare is usually assessed by three parameters namely structure, process and outcome of healthcare services (Donabedian, 1988). Quality improvement measures should preferably include all the three parameters. Consideration of all the three parameters is often absent in the current practices. The structure of the hospitals is assessed by the human and material resources available in each hospital (America's Best Hospitals, 1990). Process in hospitals has been difficult to measure by specific metrics (Green et al., 1997). Measurement may require large databases, which may not be consistently available (Palmer, 1997). A process-based approach to measure hospital performance and Intensive Care Unit (ICU) was presented by Hariharan et al. (2004) and Dey et al. (2004), respectively.

Currently, outcome-based models dominate the arena of performance measurement in the majority of healthcare institutions. Outcomes are usually evaluated by the risk-adjusted mortality rate of each hospital (Green et al., 1997). This is done by applying prognostic scoring systems in the units such as Operating Room (OR), ICU and Accident and Emergency (A\&E). Many such models exist such as Physiologic and Operative Scoring System for enUmeration of Morbidity and Mortality (POSSUM) for operative morbidity and mortality (OR); Acute Physiology and Chronic Health Evaluation (APACHE) for ICU morbidity and mortality and Trauma Injury Severity Scoring System (TRISS) for trauma patients in A\&E (Copel et al., 1991; Knaus et al., 1991; Wong et al., 1996). These systems offer logistic regression equations for calculating the predicted outcome for a particular case-mix of patients (Marik and Varon, 1999). The ratio of the observed outcome to the predicted outcome indirectly indicates the performance of the unit (Glance et al., 2002). These outcome-based models exclusively consider in a binary fashion either 'death' or 'survival' of the patient as a quality indicator. These may not be useful by themselves as an overall indicator of performance (Popovich, 2002), due to situations where, despite adequate medical care, patients may have an adverse outcome due to factors not under the control of the physicians (Brook and McGlynn, 1996). Outcome of the treatment given to the patient should only be one aspect of quality measurement rather than overall performance measurement.

In view of the above, there is a need for an uniform model, which provides for all the aspects (structure, processes and outcomes) of quality improvement from concept to implementation in order to perform better. Organisations require fostering a quality culture, which would identify issues/problems in the system dynamically, suggest solutions to those issues and develop a framework for implementation of those solutions. Moreover, relating improvement measures of each service with the strategies of the entire organisation is another challenge to healthcare services providers. Accordingly, the 
objective of this study is to develop an integrated quality management model for hospital-based healthcare services.

The rest of this paper has been organised as follows: Section 2 describes methodology, Section 3 demonstrates the role of technology in achieving business excellence, Section 4 depicts Logical Framework Analysis (LFA) and its utilities in resolving various management issues, Section 5 develops quality management models using LFA, Section 6 demonstrates the effectiveness of the model using a case study and Section 7 concludes this study by elaborating the advantages and disadvantages of the proposed model.

\section{Methodology}

This study used LFA to develop an integrated quality management model. It involved the concerned stakeholders to carry out each step of the model to identify improvement measures, plan improvement projects and implement them. This study adopts a case study method to demonstrate the effectiveness of the model.

\section{Role of technology in business management}

Technology management plays a crucial role in integrating various organisational management functions in order to achieve business excellence. Organisational innovation is driven by 'market pull' and 'technological push'. Dynamic customers' needs drive organisations for continuous improvement using new technology in order to achieve excellence. These innovative ideas are implemented through development projects in line with the organisation's competitive strategies. Organisation needs to evaluate dynamically their internal (strengths and weaknesses) and external (opportunities and threats) conditions to formulate effective strategies. The strategic projects improve the operations of organisational value chain in order to convert resources to products and services in line with the requirement of customers. Supply chain on one hand manages the internal value chain and flow of resources and on the other hand manages customers' order cycle. Figure 1 depicts the role of technology in managing the integration of various functions in order to achieve business excellence. Many researchers (Drejer et al., 2002; Hoek, 2002) have shown relationship among management of technology, operations management and supply chain management. McCarthy (2003) tried to relate innovation with the competitive mechanism of any organisation and proposed the strategy configuration chain. Customers are centre of attraction in today's business (Anderson and Loland, 2001). A business transformation model has been proposed by Spring and Sweeting (2002) focusing on customers. Technology and human interface is very crucial in order to achieve business excellence (Genus and Kaplani, 2002). Technological innovation and customer demands help formulate new supply chain strategies in line with the competitive strategies (Boer and Gertsen, 2003; Dziura, 2001). However, they require clear implementation method using project management framework (Herstatt and Christopher, 2004; Soderland, 2005). This avoids the problem implementing organisational innovation (Schuring et al., 2003). This study demonstrates strategic management of technology (Kurokawa et al., 2005) in line with the customers' requirement and capitalising organisational innovation using logical framework. 
Figure 1 Role of technology in achieving business excellence

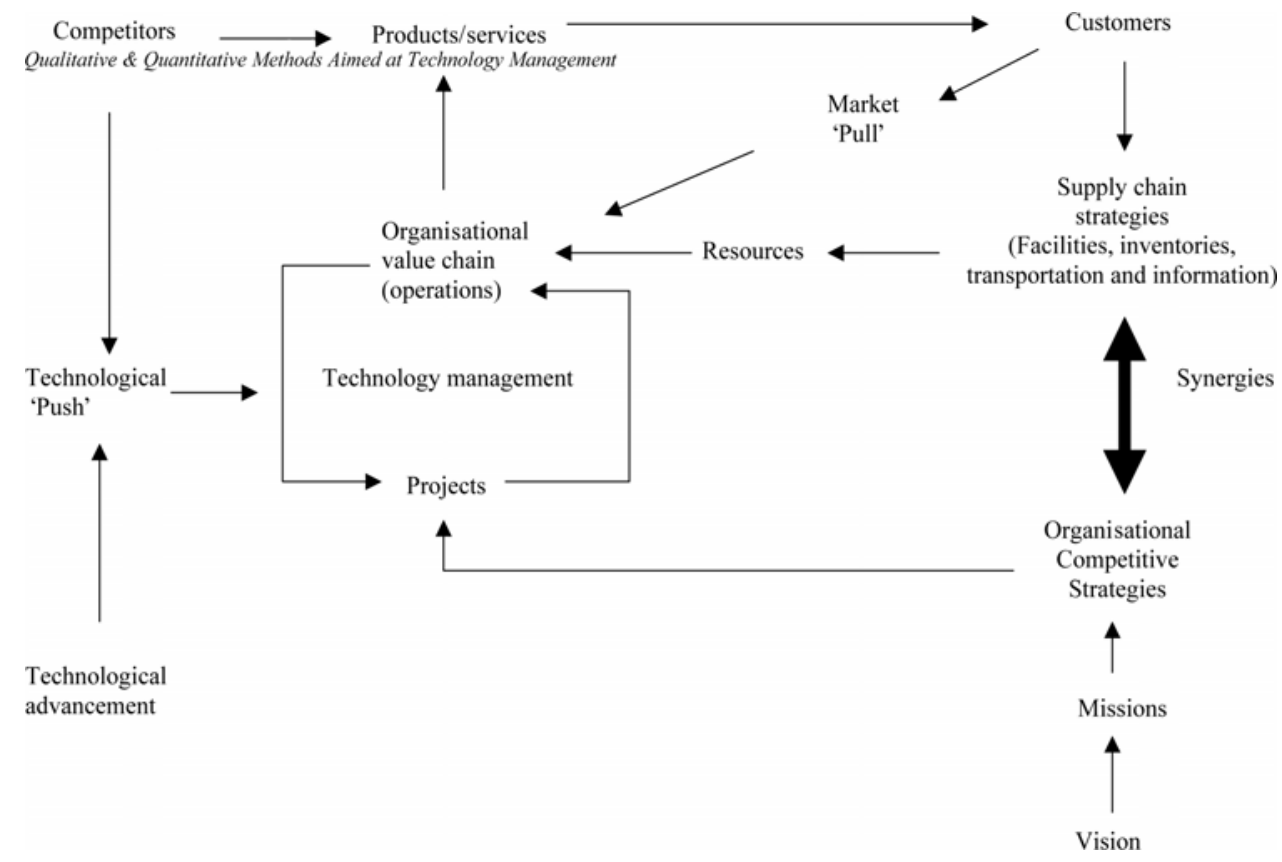

\section{The LFA}

The LFA is an effective strategic planning and project management methodology with wide applications (Akroyd, 1995a,b, 1999; Argeetey, 1998; Cordingley, 1995). It comprises an integrated package of tools for analysing and solving planning problems and for designing and managing their solutions within a stakeholder participatory framework. LFA was developed in USA and has since been adopted and adapted for use by many other donors, including the Department for International Development (DFID, 1997, 2005) in the UK. A logical framework summarises, in standard format (Appendix) what the project is going to achieve, what activities will be carried out to achieve its outputs and purpose, what resources are required, what are the potential problems which could affect the success of the project and how the progress and ultimate success of the project will be measured and verified.

The method is robust and more disciplined than traditional expert-driven planning tools. Its effectiveness is enhanced by early and intimate involvement of stakeholders in the design phase, systematic logical analysis of problems and application of a matrix in which development goals, activities, impact indicators and risk are all logically related in a succinct organisational framework (Smith, 2000).

This method is now widely used in a number of countries, as well as by the main international and bilateral aid agencies, for formulating strategies, designing regional and community development programs and investment projects (Bornstein, 2003). However, according to the authors' knowledge this study is the first application of LFA for improving services quality in general and healthcare in specific. 


\subsection{Why logical framework?}

Logical framework is an analytical management tool, which helps managers to:

1 analyse the existing situation during project preparation

2 establish a logical hierarchy of means by which objectives will be reached

3 identify the potential risks to achieve the objectives and to sustain its outcomes

4 establish how outputs and outcomes might best be monitored and evaluated

5 present a summary of the project in a standard format

6 monitor and review projects during implementation

7 communicate project information

8 make decisions across various phases of project and

9 evaluate project after completion.

The approach involves problem analysis, stakeholder analysis, developing a hierarchy of objectives and selecting a preferred implementation strategy. The product of this analytical approach is the matrix (the Logframe), which summarises the intentions and modus operandi of the project, its key assumptions and the methods of monitoring and evaluating outputs and outcomes.

In the early 1970s, LFA was first formally adopted by the USAID as a planning tool for overseas development activities. LFA has since been successfully applied as a planning and management tool by a variety of agencies. Despite some criticisms, LFA has become widely accepted and its use continues to expand into new areas. This is because it not only helps to provide a standardised summary and the logic of a project, but also applicable to various functions of any organisation (Smith, 2000). This study adds another new dimension to its application. Logical framework has been applied in many healthcare projects in the public health arena, which includes implementation of national level tuberculosis project, HIV/AIDS project, malaria project, etc. (Logical framework for TB control, 2004; AusGUIDElines: The Logical Framework, 2004; Health Care Project Tamil Nadu, India, 2004; Roll Back malaria logical framework, 2004).

\subsection{Main features of the LFA}

LFA's main strength lies in its diagnostic capability. It provides a sound basis for identifying problems and for generating appropriate solutions and interventions to achieve specific objectives and goals. It has three basic steps:

1 brainstorming for problem analysis and deriving solutions

2 formulating a logical framework from above objective analysis and

3 systematic monitoring and evaluating using key success indicators before, during and after implementation. 


\section{Quality management model using LFA}

The proposed quality management model has the following steps:

1 Identify a specific process for improvement: although to improve performance of a productive system, every process performance is required to be studied and improvement measures are to be derived, a specific process may be prioritised for improvement action.

2 Identify performance parameters: the process parameters are both objective and subjective in nature. Identifying those factors and developing a framework to analyse them are to be carried out to derive process performance.

3 Measure current performance: extensive data collection and analysis in line with the performance measurement framework with the active involvement of the process owners are to be carried out in order to measure performance of each process.

4 Identify issues related to the process not performing as desired using problem tree: the reasons for non-achievement of desired performance level are to be identified using brainstorming among the process owners. First, the macro-level problem is identified and subsequently, the root causes of that problem are identified hierarchically.

5 Derive solutions to the above problems using objective tree: subsequently, an objective tree is developed, which corresponds to the problem tree of a specific process with the involvement of the process owners.

6 Develop a logical framework using the information from the objective tree: a logical framework is then formulated from the information in the objective trees. The logical framework matrix justifies the improvement project as well as providing an overview of the project plan.

7 Develop a detailed project plan for implementation for improving process performance: information from logical framework along with other studies (survey, design and detailed engineering) helps develop detailed project plan.

8 Obtain approval of the competent authority: approval from competent authority on the basis of project plan ensures of resource deployment and management commitment for performance improvement. While approving the management ensures link between process improvement projects and organisational strategies both in short and long terms.

9 Implement, monitor and evaluate the improvement projects: projects are then implemented with the involvement of specialised groups (from the matrix organisation structure) along with consultants, contractors and suppliers (in line with the requirements), which ensures employee involvement in improving process performance.

10 Measure the performance of the process using the earlier parameters and analyse for continuous improvement: process performance is dynamically monitored for the purpose of continuous improvement.

Figure 2 depicts the proposed quality management model using logical framework. 
Figure 2 Quality management model for improving process performance

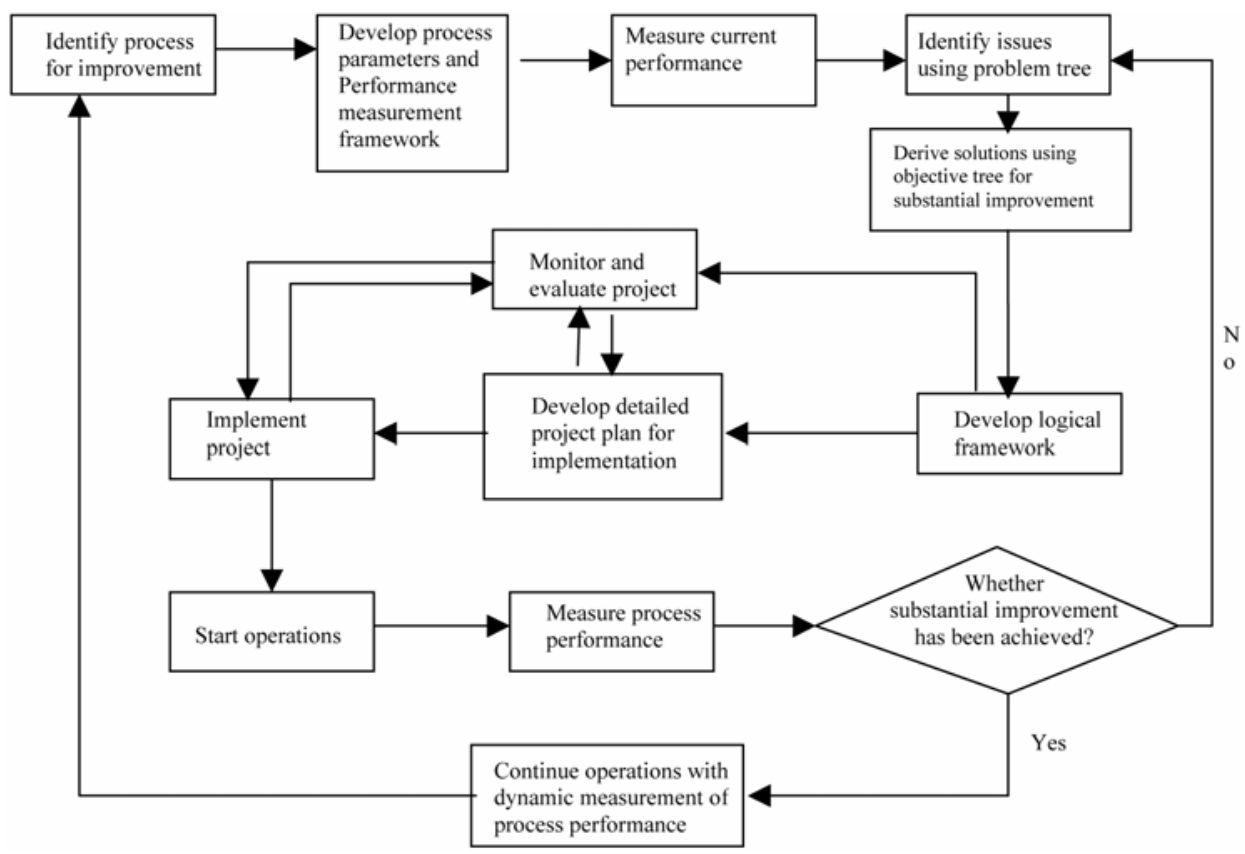

\section{Application of the model in healthcare services}

The effectiveness of the model has been demonstrated through applications in the healthcare services of a multidisciplinary tertiary care hospital in Barbados.

Barbados is an island of the eastern Caribbean, with a population of 268,000. It is an English-speaking country of the British Commonwealth with a high quality-of-life index. The Queen Elizabeth Hospital is a 650-bed tertiary care centre, affiliated to the University of West Indies and a referral centre for several Caribbean countries. The surgical ICU in the Queen Elizabeth Hospital Barbados, is a six-bed unit, admitting patients from all surgical specialties.

The analysis was undertaken with involvement of two hospital managers, five doctors, three nurses and two support staff in workshop environment using several structured brainstorming sessions. All the stakeholders involved in the case study had more than 15 years of experience in their respective fields. The researchers worked as facilitators of the brain storming sessions.

The LFA approach in developing a quality management model was undertaken using the following ten steps.

Step 1 After detailed discussion with the hospital management on quality improvement, the researchers decided to study healthcare services in the three following critical care units:

1 Operating Rooms

2 Intensive Care Unit and

3 A\&E unit. 
They were selected on the basis of importance and their inferior performance with respect to overall hospital performance (Hariharan et al., 2004).

Step 2 In healthcare services, process performance can be measured by throughput (number of patients being treated in a given period), patient comfort (patient-focused care) and outcome (quality of treatment) (Hariharan et al., 2004, 2005). In this study, a thorough brainstorming session among the clinical professionals revealed the process parameters of the units under study. The process parameters for operation room utilisation were 'surgery on-time' and 'minimal patient-adverse outcome'. 'Patient throughput' and 'minimal patient-adverse outcome' were the process parameters for A\&E services. The process parameters of ICU were 'reduced morbidity and mortality' and 'increased patient comfort'.

Step 3 The performance data analysis of all the above processes revealed that currently, all the three process were not performing to the desired level. Recent audit revealed that in the OR, both the performance parameters were below target levels of customer (patients and clinician) satisfaction (Ramesh et al., 2005). Delay in treating patients and increased adverse patient outcomes were recognised as the problems in the A\&E unit (Banerjea, 2004). Increased morbidity and mortality (measured using standard mortality ratio) and decreased patient satisfaction were observed in the ICU of the hospital under study (Hariharan et al., 2002).

Step 4 Each process was separately studied with the involvement of stakeholder representatives from all the clinical professionals (including medical, nursing and paramedical personnel). These practitioners were involved in brainstorming sessions. First, they identified macro-level issue for each process and subsequently derived root causes of macro issues. This helped to develop a hierarchy of issues (problem tree) for each process.

Figure 3 shows the problem tree of the OR utilisation process as derived by the stakeholders. The root-cause analysis revealed that lack of motivation of doctors, nurses and support staff, inappropriate scheduling and inefficient OR management were the basic reasons for not achieving desired performance. Figure 4 shows the problem tree of A\&E cases of the hospital under study. Delay in consultation, improper triaging, delay in patients disposal and inadequate infrastructure were considered by the stakeholders as the major reasons for unsatisfactory performance of the A\&E services. The stakeholders identified the root causes of increased morbidity and mortality and decreased patient comfort in the ICU. They were as follows:

- $\quad$ problem related to doctors, nurses and support staff

- $\quad$ inadequate ICU drugs and equipment

- $\quad$ improper maintenance of equipment and facilities

- problem caused by other related units (laboratory, A\&E unit, operation room, etc.)

- absence of treatment protocol and

- improper communication.

Figure 5 shows the problem tree of the ICU as developed by the stakeholders.

Step 5 Subsequent brainstorming sessions enabled the stakeholders to formulate the objective trees (hierarchy of the suggested solutions). Each level of the objective tree indicates solutions to corresponding level of the problem tree. 
Figure 6 shows the objective tree of the OR utilisation process. The managers and clinicians derived that new recruitment policy, fair salaries, improved working conditions, promotion and reward system, team development activities, Information Technology (IT)-based scheduling programme, trained operation room management team, preventive maintenance programme for all equipment and OR system, and purchasing of state-of-the-art equipment would improve the performance of the entire unit.

Figure 3 Problem tree for operating rooms

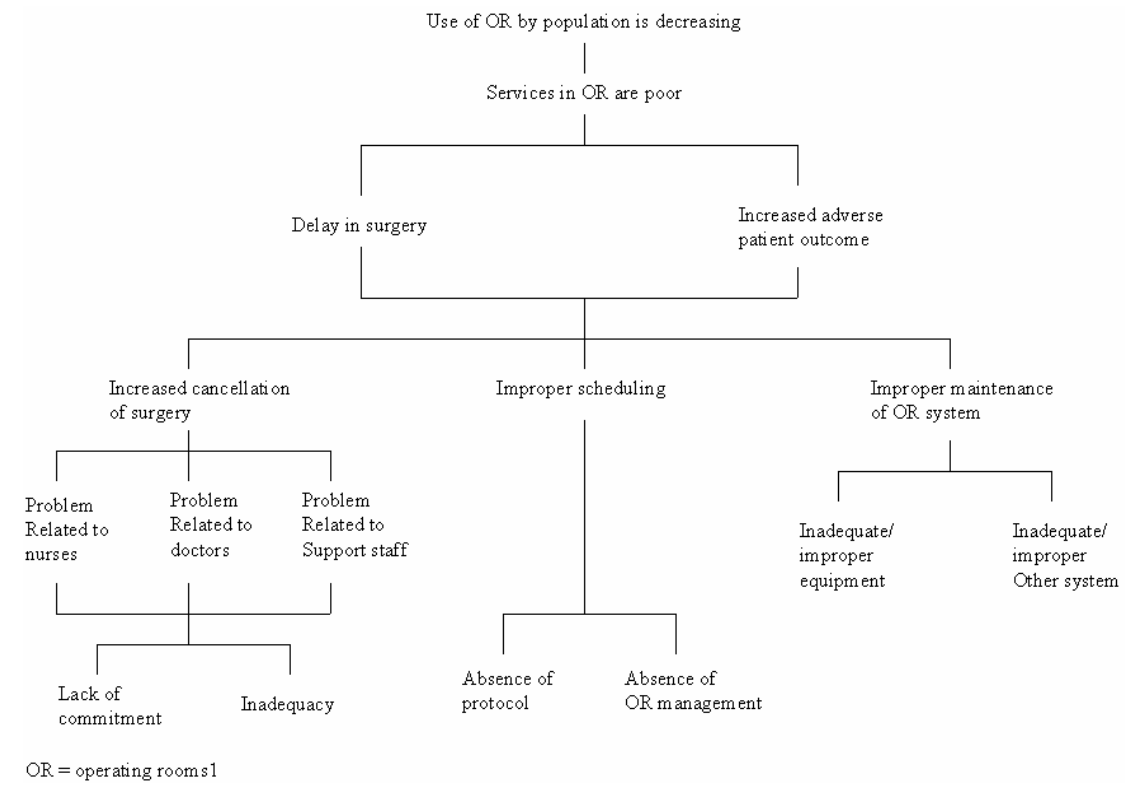

Figure 4 Problem tree for Accident and Emergency unit

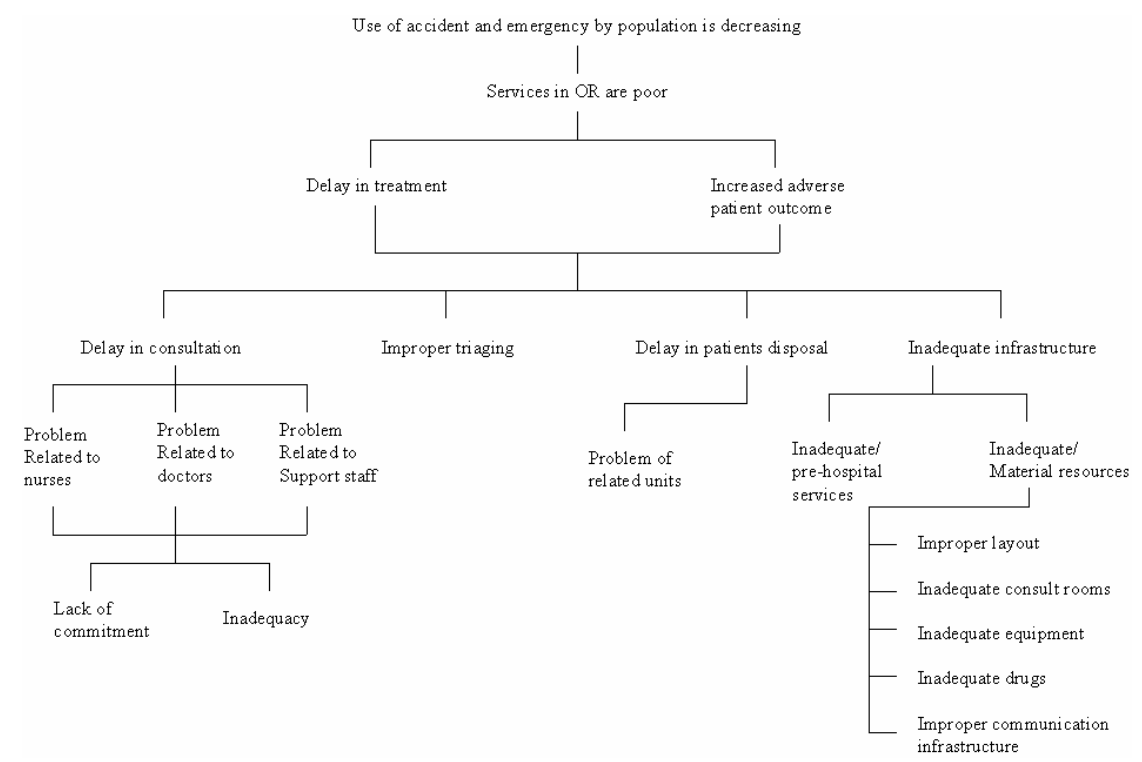


Figure 5 Problem tree for Intensive Care Unit (ICU)

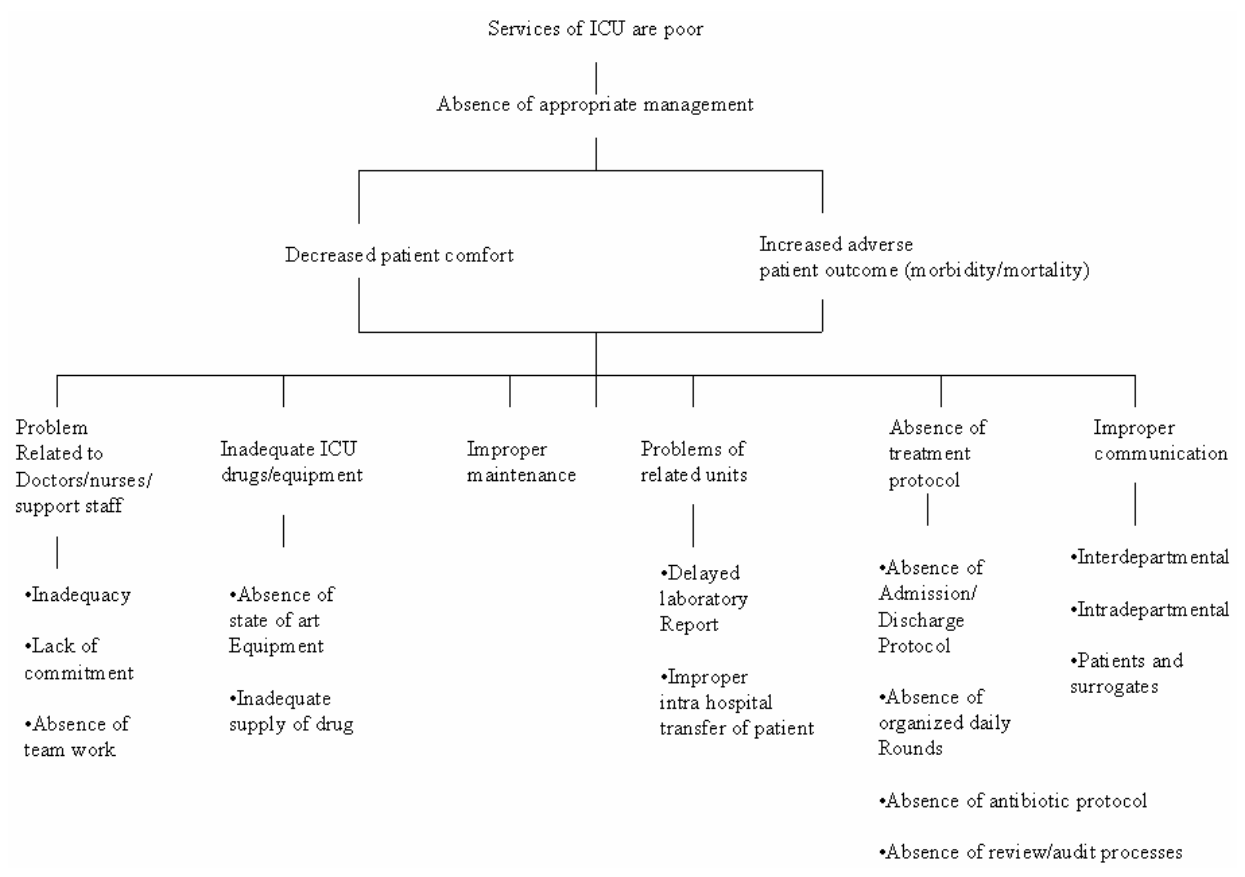

Figure 6 Objective tree for operating rooms

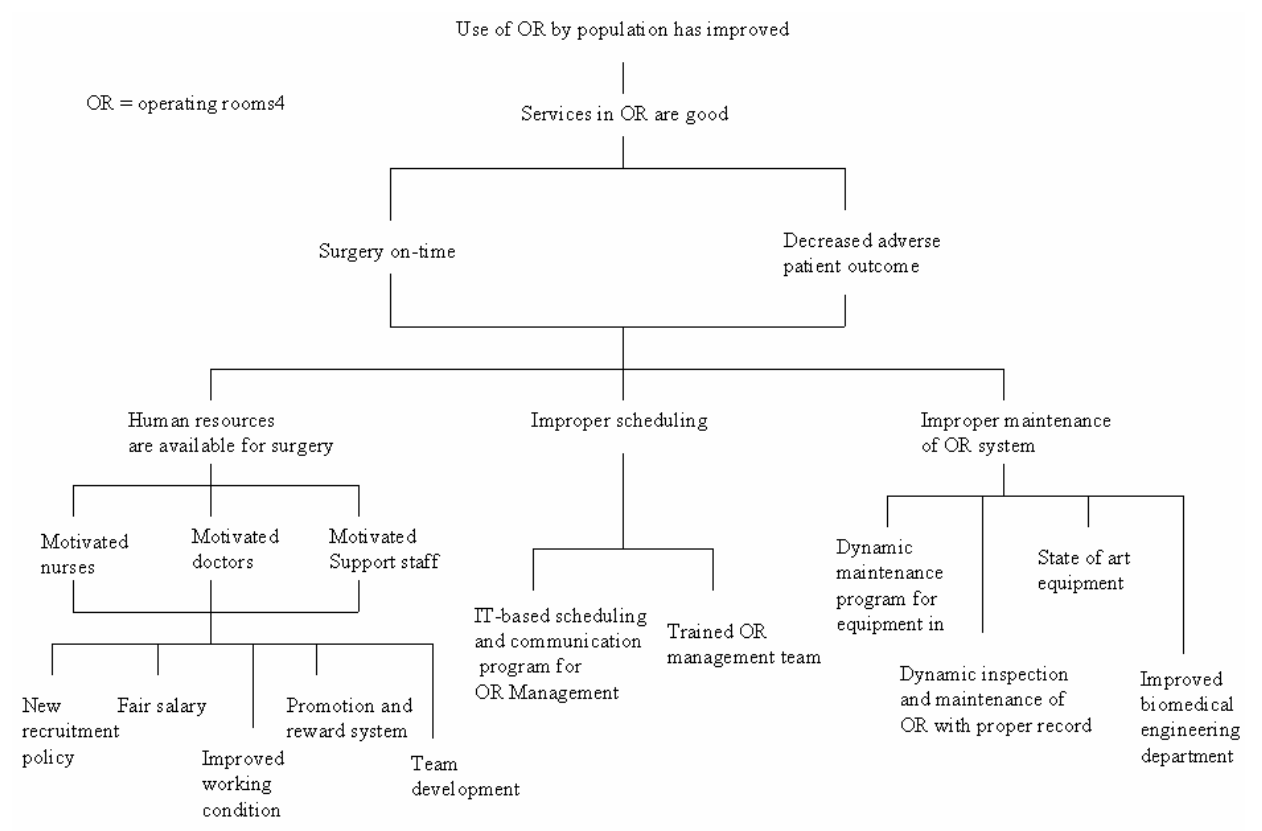

Figure 7 demonstrates the objective tree of the A\&E of the hospital under study. Additional recruitment, training and team building activities were considered as the solutions to delay in consultation. They revealed that appropriate triaging, improvement 
of functioning of other related units like ICU, OR, etc. efficient prehospital services like ambulance services, communication services and adequate infrastructure would make productive A\&E services.

Figure 7 Objective tree for Accident and Emergency unit

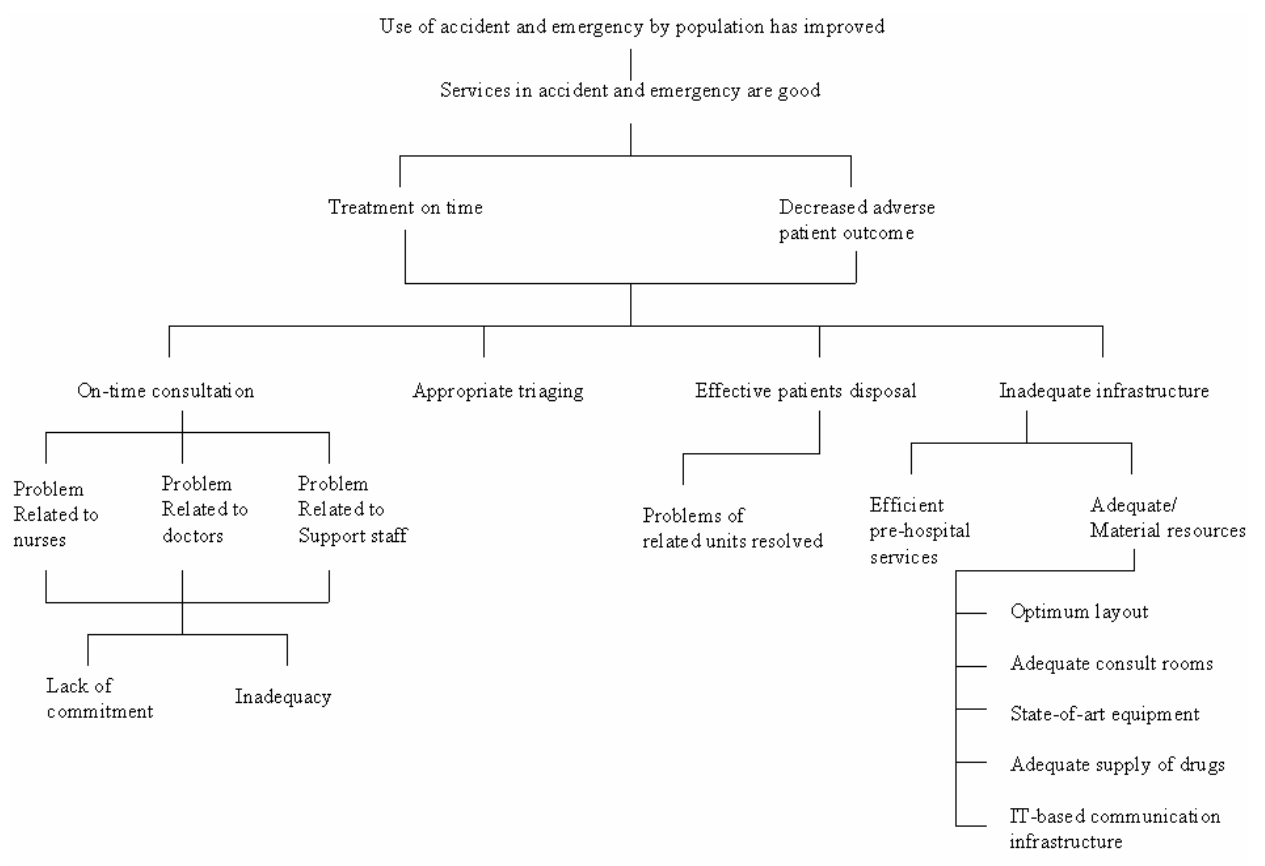

Figure 8 shows the objective tree for the ICU as developed by the stakeholders in the brainstorming session. It revealed that motivated clinical professionals with adequate materials resources (drug and disposables) and facilities (infrastructure and equipment) using standardised treatment protocol could improve the ICU performance substantially.

Step 6 The next step involved the development of the logical framework from the objective tree. The top level of the objective tree formed the goal of the project, the next level comprised the project purpose, the last level in the hierarchy formed the activities/inputs in the logical framework and the level above the last formed the project outputs. The other information for formulating logical framework was gathered from other planning process with the stakeholders' involvement. The first column of the logical framework was the objectives covering goal, purpose, outputs and inputs for improvement project in each level. The second column depicted the objective indicators of goal, purpose, outputs and inputs. The third column was the means of verification of the indicators of each level. The last column represented the assumptions of each level.

Tables 1, 2 and 3 give the logical framework of the OR utilisation process, the A\&E services and ICU of hospital under study.

Step 7 Although the main purpose of developing logical framework was to present project information in a nutshell in order to get approval from the competent authority, it formed the basis for the development of a detailed project plan (project specification, 
schedule and budget). The stakeholders developed detailed project plans and budget for the three units under study using information in the LFA.

Figure 8 Objective tree for Intensive Care Unit (ICU)

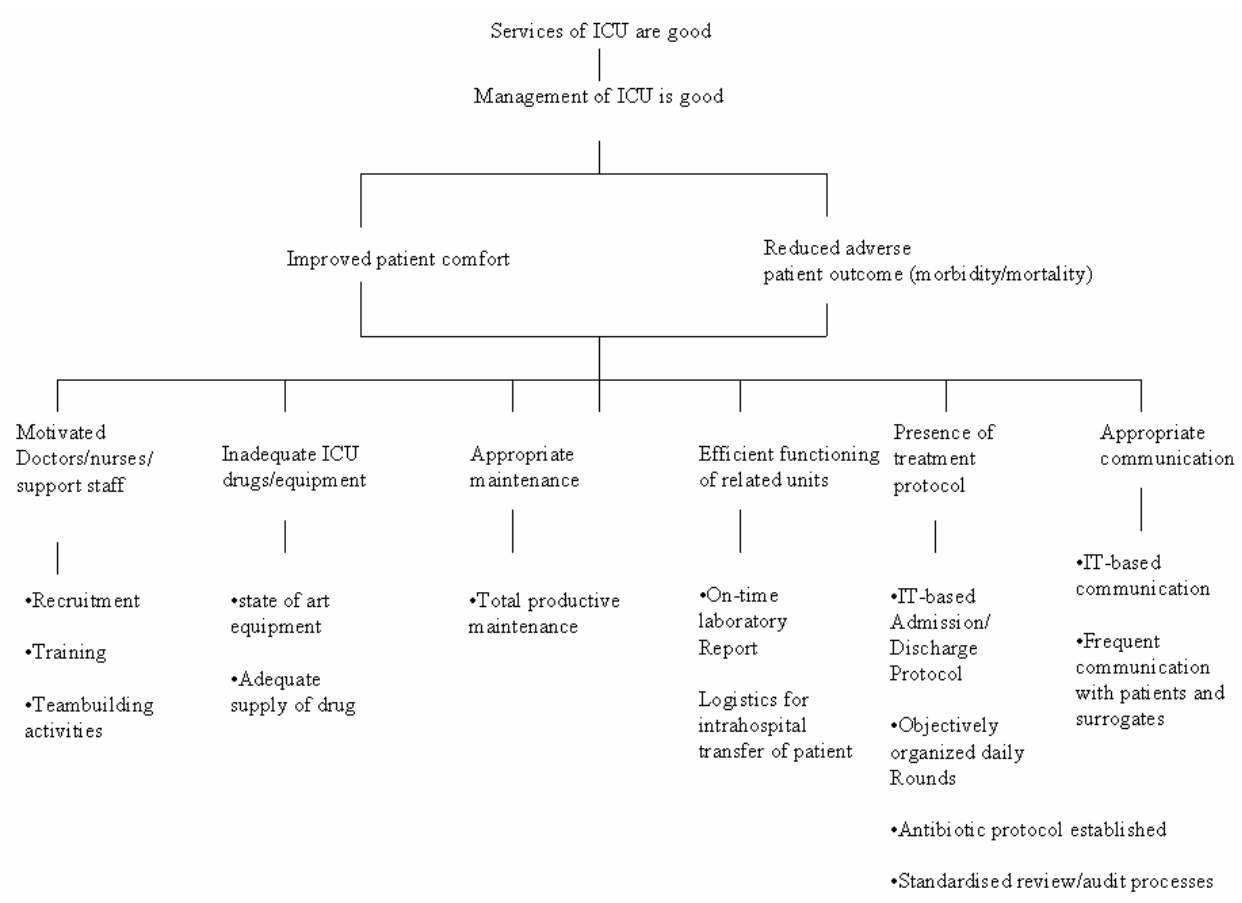

Step 8 Project plan along with the logical framework of each unit was put up to the hospital management for approval. The logical framework provided the rational of the improvement projects and also provided the means for project monitoring and evaluation. After a thorough analysis of project plan and linking it with the strategic goals of the organisation, the hospital management approved the improvement projects with a few amendments in the plans.

Step 9 A detailed implementation plans were subsequently worked out for each unit. Improvement projects were then implemented with the active participation of various project participating agencies (contractors, suppliers, consultants, etc.). The project was constantly monitored and evaluated using the parameters set forth in the logical framework.

Step 10 Upon completion of the improvement projects, they were linked with the existing services in each unit. Subsequently, performance measurement revealed that there was improvement in all the three units in terms of patients through put, reduced adverse patient occurrence and patients' satisfaction.

In the operation room, on-time surgery had improved by $40 \%$ and there were no patient-adverse outcome subsequent to implementation of quality improvement projects. In the A\&E services also there was no report of patient-adverse outcome and the patient throughput was increased by $25 \%$ subsequent to implementation of quality improvement projects. In the ICU, morbidity and mortality were considerably reduced (measured using Standard Mortality Ratio) and patient satisfaction index was improved by $35 \%$. 
Table 1 Logical framework for Operating Rooms

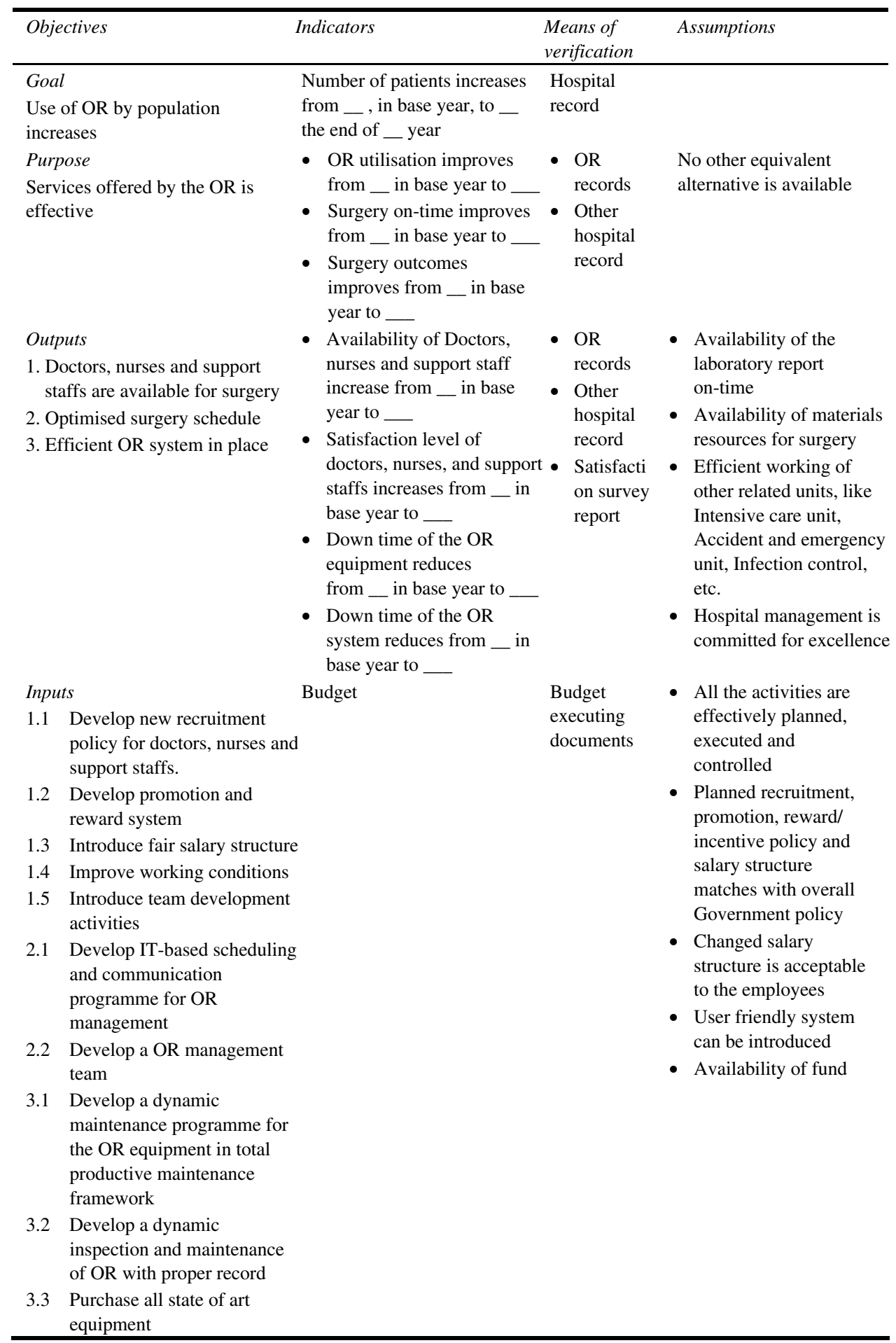


Table 2 Logical framework for Accident and Emergency

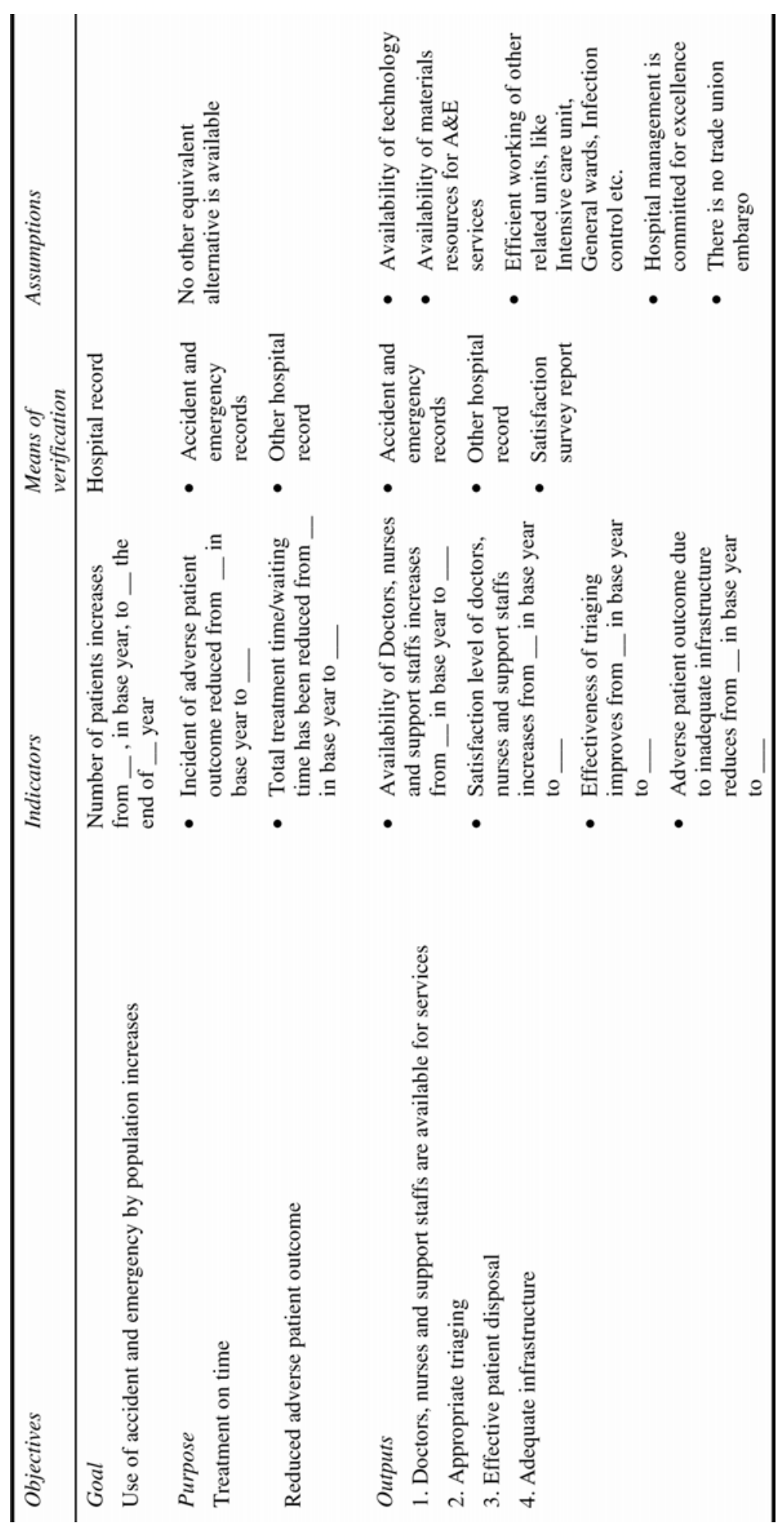


60

P.K. Dey, S. Hariharan and W. Ho

Table 2 Logical framework for Accident and Emergency (continued)

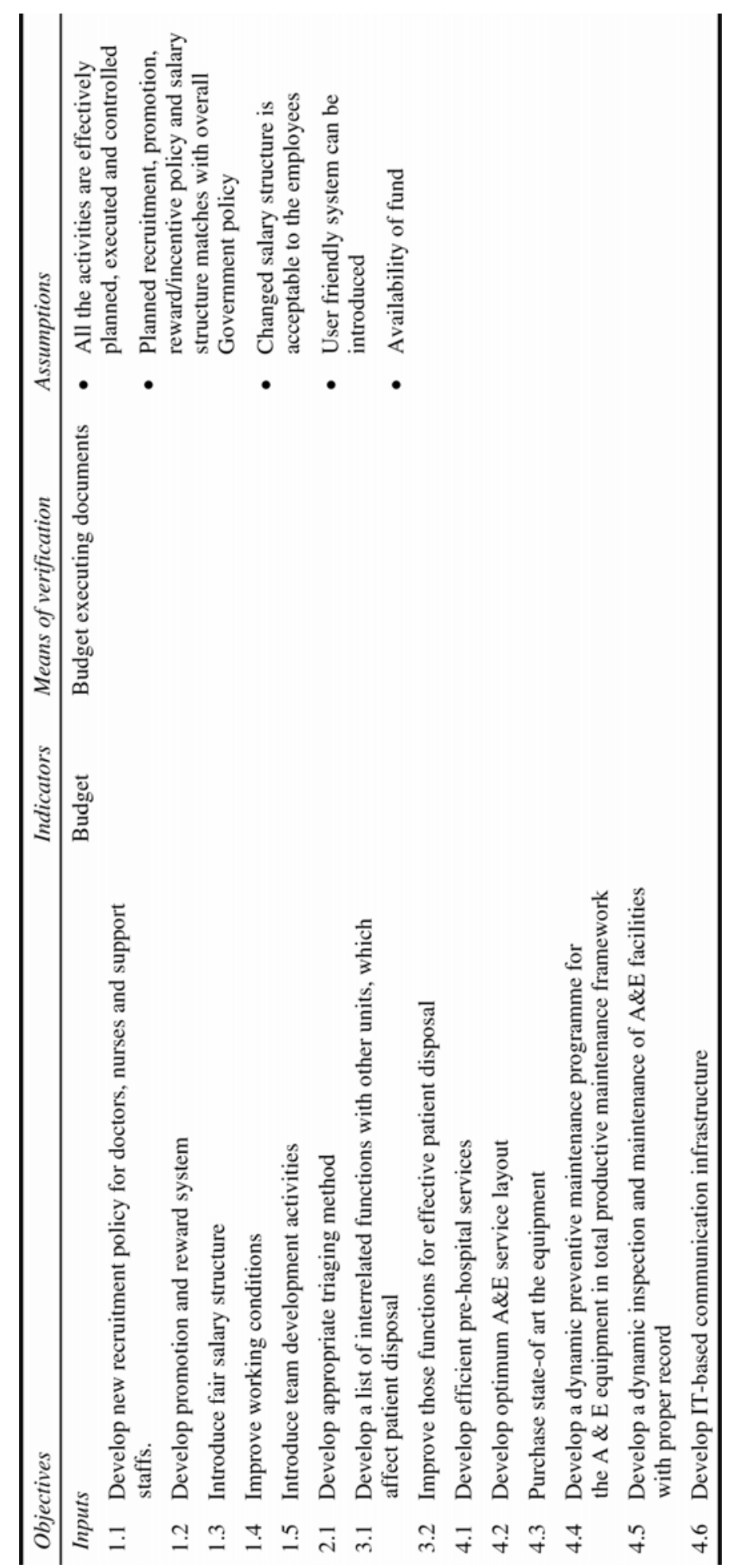


Table 3 Logical Framework for Intensive Care Unit (ICU)

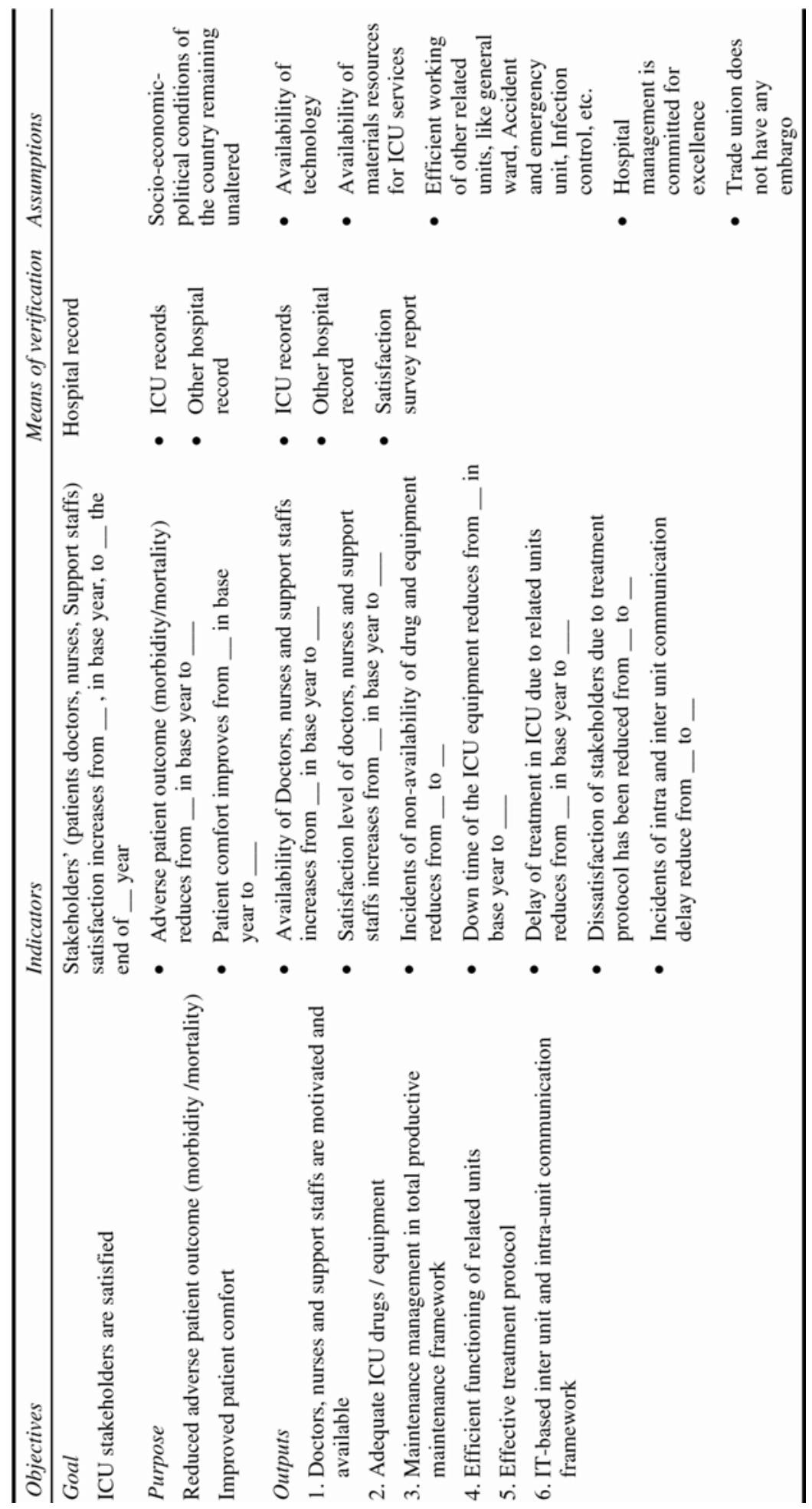


Table 3 Logical Framework for Intensive Care Unit (ICU) (continued)

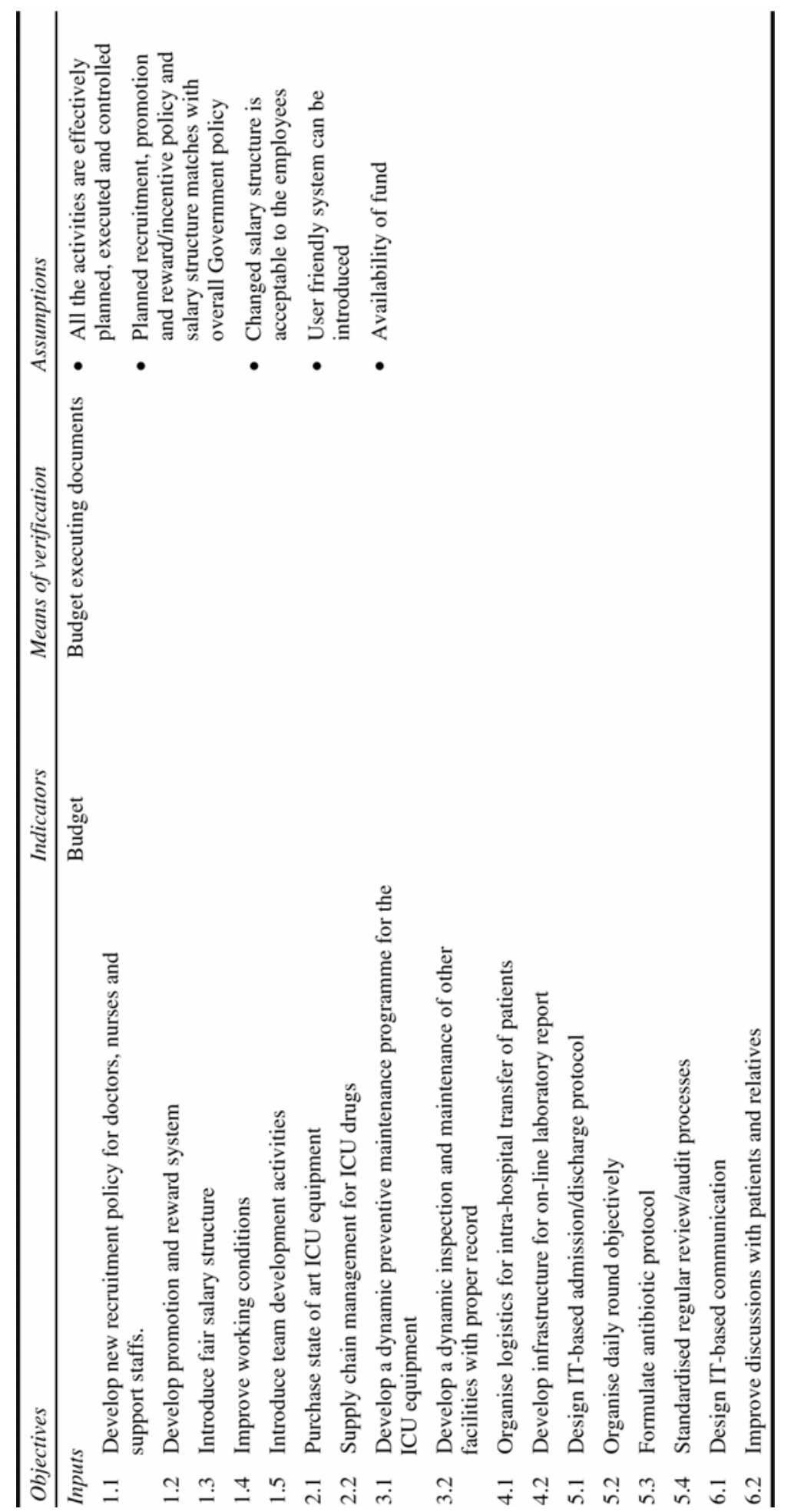




\section{Discussion and conclusion}

Quality management practices in healthcare services are characterised by their fragmented approach, absence of holistic and uniform framework and without any link to the strategic intent of the organisation as a whole. In order to improve service performance, the management should consider all the quality parameters with respect to structure, process and outcomes. Additionally, the method should provide a framework for identifying and analysing quality issues and provide solutions to those issues with the involvement of the concerned stakeholders. The suggested solutions should be transformed to formulate a project, which can be linked with the overall organisational strategy. Quality management using the logical framework develops an integrated approach to identifying and analysing issues, suggesting solutions and formulating projects with the involvement of the concerned stakeholders. The 'Objectively verifiable indicators' and 'Means of Verification' column in the framework necessitate appraisal in structure, process and outcomes measures of quality. Additionally, LFA also facilitates the monitoring and evaluation of project dynamically for CQI of the process. CQI requires continuous performance appraisal through data collection and analysis to ascertain that the improvement measures have been appropriately and effectively implemented (Slovensky, 1996).

LFA offers a uniform model, which can be applied to most of the healthcare units covering both clinical and non-clinical departments. It can be networked with the organisation's ICT framework in order to improve the involvement of concerned stakeholders in quality improvement.

Figure 9 Generalised quality improvement model for organisation

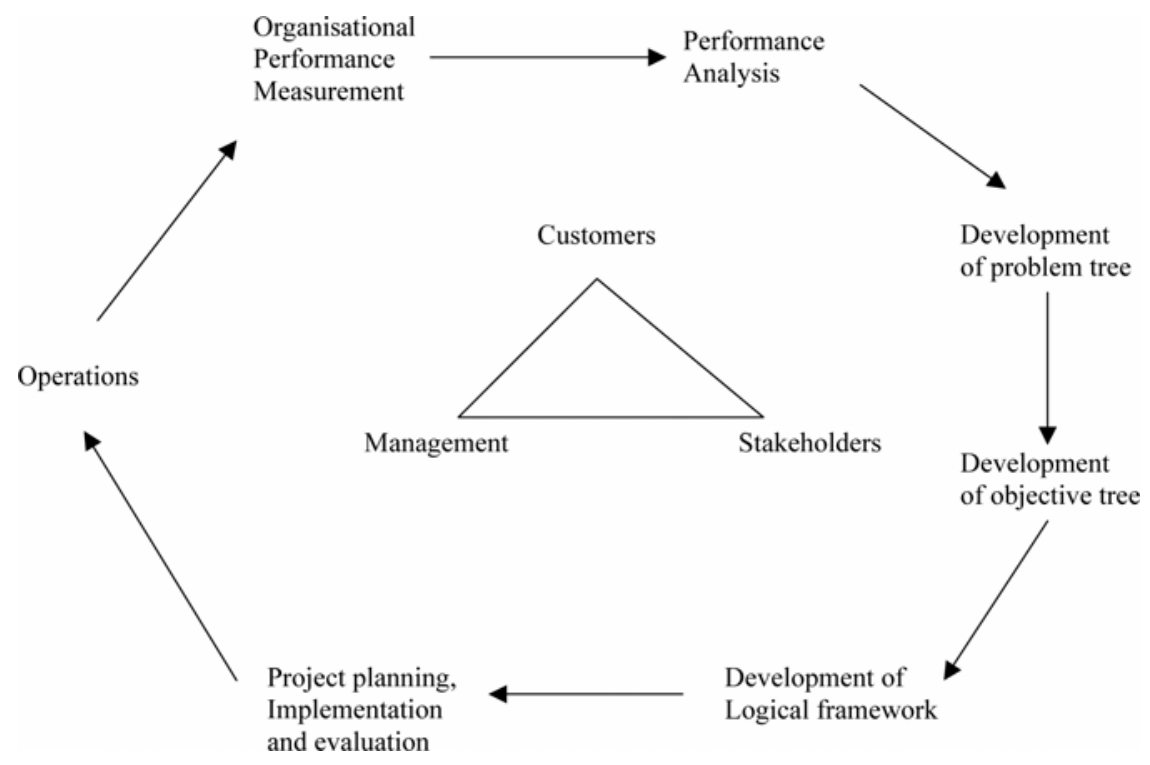

The proposed quality management approach establishes a link between the organisational learning, resource-based theory and strategic management, which is considered helpful for any organisation to keep an edge over other organisations in this competitive environment (Bitencourt, 2003). 
A similar approach may be adopted for managing quality in other service sectors. Identifying problems, suggesting solutions and developing logical framework should be undertaken with the involvement of the representatives of the stakeholders using standard brainstorming sessions. Figure 9 shows a generalised framework for organisational quality improvement programme. Developing a customer focus performance measurement framework, analysing performance with stakeholders participation, developing logical framework and implementing projects with management approval ensure superior performance of the organisations.

The proposed holistic quality improvement model using LFA provides a uniform approach to improve quality of every process. It not only identifies issues pertaining to each process for superior performance and suggests solutions, but also derives a planning framework for implementing improvement projects along with monitoring and evaluation opportunities for dynamic decision making. This ensures superior performance of the entire system upon the implementation of each improvement project. The additional advantage of LFA is that it involves the process owners during analysis (to carry out the stated ten steps). This reveals the real problems of the process and suggests practical cost-effective solutions and also ensures practicing of the improvement measures upon implementation. The model incorporates the strategic intent of the organisation by involving management in decision-making process while approving the project proposal. This ensures management commitment to quality improvement projects during planning, implementation and operations. LFA provides a CQI environment in the entire organisation with customer focus. LFA incorporates conventional quality management tools to identify problems and suggest solutions. LFA helps to analyse cost of quality improvement and overall benefit of the organisation. The suggested approach does not provide any prioritising scheme improvement projects. However, the stakeholders can recommend their priority while proposing the project for approval and management makes their own choice with the consideration of overall goal of the organisation.

\section{References}

Akroyd, D. (1995a) 'The Logical Framework Approach and the post-evaluation of health sector projects by the, African Development Bank', Project Appraisal, Vol. 10, No. 4, pp.210-222.

Akroyd, D. (1995b) 'Steps toward the adoption of Logical Framework Approach in the African Development Bank: some illustrations for agricultural sector projects', Project Appraisal, Vol. 10, No. 1, pp.19-30.

Akroyd, D. (1999) 'Logical framework approach to project planning, socio-economic analysis and to monitoring and evaluation services: a smallholder rice project', Impact Assessment and Project Appraisal, Vol. 17, No. 1, pp.54-66.

America's Best Hospitals (1990) US News and World Report, 30 April, pp.51-85.

Anderson, B. and Loland, H.S. (2001) 'A study of the use and effect of quality improvement tools', International Journal of Technology Management, Vol. 22, Nos. 1/2/3, pp.212-232.

Argeetey, E. (1998) 'Consultative processes in community development in Northern Ghana', Community Development Journal, Vol. 33, No. 4, pp.301-333.

Australian Government (2004) 'AusGUIDElines: The Logical Framework Approach 3', Available at: http://www.ausaid.gov.au/. Accessed on February 2004.

Banerjea, K. (2004) 'Process reengineering of accident and emergency services in the Queen Elizabeth Hospital, Barbados', Unpublished DM Thesis, University of the West Indies, Barbados. 
Berwick, D.M. (1998) 'Developing and testing changes in the delivery of care', Annals of Internal Medicine, Vol. 128, pp.651-666.

Bitencourt, C.C. (2003) 'Resource-based theory and strategic management: the link with organizational learning', International Journal of Innovation and Learning, Vol. 1, No. 2, pp.166-176.

Boer, H. and Gertsen, F. (2003) 'From continuous improvement to continuous innovation: a (retro)(per)spective', International Journal of Technology Management, Vol. 26, No. 8, pp.805-827.

Bornstein, L. (2003) 'Management standard and development practices in South African aid chain', Public Administration and Development, Vol. 23, No. 5, pp.393-404.

Brook, R.H. and McGlynn, E.A. (1996) 'Measuring quality of care', New England Journal of Medicine, Vol. 335, pp.966-999.

Chen, H.K., Chen, H.Y., Wu, H.H. and Lin, W.T. (2004) 'TQM implementation in a healthcare and pharmaceutical logistics organization: the case of zuellig Pharma in Taiwan', Total Quality Management, Vol. 15, Nos. 9-10, pp.1171-1178.

Copeland, G.P., Jones, D. and Walters, M. (1991) 'POSSUM: a scoring system for surgical audit', British Journal of Surgery, Vol. 78, pp.355-360.

Cordingley, D. (1995) 'Incorporating the Logical Framework into the Management of technical co-operation projects', Project Appraisal, Vol. 10, No. 2, pp.103-112.

Coughlan, P., Harbison, A., Dromgoole, T. and Duff, D. (2001) 'Continuous improvement through collaborative action learning', International Journal of Technology Management, Vol. 22, No. 4, pp.285-302.

Dey, P.K., Hariharan, S., Kumar, A.Y. and Moseley, H.S.L. (2004) 'Performance measurement of intensive care services in hospital: the case of Barbados', International Journal of Service Technology Management, Vol. 5, Nos. 5/6, pp.579-595.

DFID (1997) Guidelines on Humanitarian Assistance, published in May 1997 includes guidance on preparing $\log$ frames, and is available at: http://62.189.42.51./DFIDstage/faqs/files/ guidelines_on_humanitarian_assistance_v5.0a.doc.

DFID (2005) Chapter on Logical Frameworks in their Tools for Development Series, Available at: http://62.189.42.51/DFIDstage/FOI/tools/chapter_05_frame.htm.

Donabedian, A. (1988) 'The quality of care - How can it be assessed?' Journal of American Medical Association, Vol. 260, pp.1743-1748.

Drejer, A., Bannett, D. and Sohal, A. (2002) 'Impacts and relationships between three evolving disciplines', International Journal of Technology Management, Vol. 23, Nos. 1/2/3, pp.2-20.

Dziura, M.J. (2001) 'Innovation: sources and strategies', International Journal of Technology Management, Vol. 21, Nos. 5/6, pp.612-627.

Evan, J.R. and Lindsay, W.M. (2002) The Management and Control of Quality, 5th edition, USA: Thompson Learning.

Feeney, A. and Zairi, M. (1996) 'TQM in Healthcare', Journal of General Management, Vol. 22, pp.35-47.

Fernandes, C.M.B. and Christenson, J.M. (1995) 'Use of continuous quality improvement to facilitate patient flow through the triage and fast-track areas of an emergency department', Journal of Emergency Medicine, Vol. 13, pp.847-855.

Fernandes, C.M.B. and Christenson, J.M. (1996) 'Continuous quality improvement reduces length of stay for fast-track patients in an emergency department', Academic Emergency Medicine, Vol. 3, pp.258-263.

Genus, A. and Kaplani, M. (2002) 'Managing operations with people and technology', International Journal of Technology Management, Vol. 23, Nos. 1/2/3, pp.189-200.

Glance, L.G., Osler, T.M. and Dick, A. (2002) 'Rating the quality of intensive care units: Is it a function of the intensive care scoring system?' Critical Care Medicine, Vol. 30, pp.1976-1982. 
Green, J., Wintfield, N., Krasner, M. and Wells, C. (1997) 'In search of America's Best Hospitals - the promise and reality of quality assessment', Journal of American Medical Association, Vol. 277, pp.1152-1155.

Hariharan, S., Dey, P.K., Moseley, H.S.L., Kumar, A.Y. and Gora, J. (2004) 'A new tool for measurement of process-based performance of multispecialty tertiary care hospitals', International Journal of Health Care Quality Assurance, Vol. 17, No. 6, pp.302-312.

Hariharan, S., Dey, P.K., Moseley, H.S.L. and Kumar, A.Y. (2005) 'Analytic hierarchy process as a tool for the performance measurement on intensive care services in hospital', Critical Care Medicine, Vol. 20, No. 2, pp.117-124.

Hariharan, S., Moseley, H.S.L. and Kumar, A.Y. (2002) 'Outcome evaluation in a surgical intensive care unit in Barbados', Anaesthesia, Vol. 57, pp.434-441.

Health Care Project Tamil Nadu, India (2004) Volume III, Women in Development - ANNEX IV: Logical Framework, Available at: http://www.um.dk/danida/. Accessed on February 2004.

Herstatt, C. and Christopher, L. (2004) 'Management of 'technology push' development projects', International Journal of Technology Management, Vol. 27, Nos. 2/3, pp.155-175.

Hoek, R.I.V. (2002) 'Using information technology to leverage transport and logistics service operations in the supply chain: an empirical assessment of the interrelation between technology and operations management', International Journal of Technology Management, Vol. 23, Nos. 1/2/3, pp.207-222.

Knaus, W.A., Wagner, D.P., Draper, E.A., Zimmerman, J.E., Bergner, M. and Bastos, P.G. (1991) 'The APACHE III prognostic system. Risk prediction of hospital mortality for critically ill hospitalized adults', Chest, Vol. 100, pp.1619-1636.

Kurokawa, S., Pelc, K.I. and Fujisue, K. (2005) 'Strategic management of technology in Japanese firms: literature review', International Journal of Technology Management, Vol. 30, Nos. 3/4, pp.223-247.

Lange Ros, E. and Boer, H. (2001) 'Theory and practice of continuous improvement in shop-floor teams', International Journal of Technology Management, Vol. 22, No. 4, pp.244-358.

Logical framework for TB control (2004) Task Force on the Communicable Disease Control in the Baltic Sea Region, Available at: http://www.baltichealth.org. Accessed on February 2004.

Lurie, J.D., Merrens, E.J., Lee, J. and Splaine, M.E. (2002) 'An approach to hospital quality improvement', Medical Clinics of North America, Vol. 86, pp.825-845.

Marik, P.E. and Varon, J. (1999) 'Severity scoring and outcome assessment: computerized predictive models and scoring systems', Critical Care Clinics, Vol. 15, pp.633-646.

McCarthy, I.P. (2003) 'Technology management - a complex adaptive systems approach', International Journal of Technology Management, Vol. 25, No. 8, pp.728-745.

Palmer, R.H. (1997) 'Process-based measures of quality: the need for detailed clinical data in large health care databases', Annals of Internal Medicine, Vol. 127, pp.733-738.

Popovich, M.J. (2002) 'If most intensive care units are graduating with honors, is it genuine quality or grade inflation?' Critical Care Medicine, Vol. 30, pp.2145-2146.

Ramesh, J., Walrond, E.R. and Hariharan, S. (2005) 'Evaluation of the reasons for the delays and cancellations of surgeries in a developing country', International Journal of Clinical Practice, Vol. 59, No. 6, pp.716-720.

Re, R.N. and Krousel-Wood, M.A. (1991) 'How to use continuous quality improvement theory and statistical quality control tools in a multidisciplinary clinic', QRB Quality Review Bulletin, Vol. 16, pp.391-397.

Roll Back malaria logical framework (2004) Available at: http://www.doh.gov.za. Accessed on February 2004.

Schuring, R.W., Harbers, C., Kruiswijk, M., Rajinders, S. and Boer, H. (2003) 'The problem of using hierarchy for implementing organizational innovation', International Journal of Technology Management, Vol. 26, No. 8, pp.903-917. 
Slovensky, D.J. (1996) 'Quality assessment and improvement', in M. Abdelhak, S. Grostick, M.A. Hanken and E. Jacobs, E. (Eds). Health Information: Management of a Strategic Resource, Philadelphia: WB Saunders Company, pp.320-357.

Smith, P. (2000) 'A comment on the limitation of the logical framework method, in reply to Gaper, and to Bell', Public Administration and Development, Vol. 20, No. 5, pp.439-441.

Snelson, E. (1992) 'Quality assurance implications of federal peer review laws: the Health Care Quality Improvement Act and the National Practitioner Data Bank', Journal of Quality Assurance and Utilization Review, Vol. 7, pp.2-11.

Soderland, J. (2005) 'What project management really is about: alternative perspectives on the role and practice of project management', International Journal of Technology Management, Vol. 32, Nos. 3/4, pp.371-387.

Spring, M. and Sweeting, R.C. (2002) 'Empowering customers: portals, supply networks and assemblers', International Journal of Technology Management, Vol. 23, Nos. 1/2/3, pp.113-128.

Van Matre, J.G. (1992) 'The D*A*T approach to total quality management', Journal of American Health Information Management Association, Vol. 63, pp.38-44.

Wong, D.T., Barrow, P.M., Gomez, M. and McGuire, G.P. (1996) 'A comparison of the Acute Physiology and Chronic Health Evaluation (APACHE II) score and the Trauma-Injury Severity Score (TRISS) for outcome assessment in intensive care unit trauma patients', Critical Care Medicine, Vol. 24, pp.1642-1648. 


\section{Appendix}

\section{Structure of Logical Framework Matrix}

\begin{tabular}{|c|c|c|c|}
\hline Narrative summary & $\begin{array}{l}\text { Key performance } \\
\text { indicators }\end{array}$ & Means of verification & Assumptions/risks \\
\hline $\begin{array}{l}\text { Goal } \\
\text { The overall } \\
\text { development } \\
\text { programme or } \\
\text { strategy goal }\end{array}$ & $\begin{array}{l}\text { Indicators } \\
\text { (standardised) that } \\
\text { measure } \\
\text { achievement of the } \\
\text { desired goal }\end{array}$ & $\begin{array}{l}\text { Ex-post evaluation of } \\
\text { the project }\end{array}$ & $\begin{array}{l}\text { Key factors in the } \\
\text { wider operating } \\
\text { environment usually } \\
\text { macro and extraneous } \\
\text { factors to the project }\end{array}$ \\
\hline $\begin{array}{l}\text { Purpose } \\
\text { Statement of the } \\
\text { project's } \\
\text { outcome - its } \\
\text { immediate impact }\end{array}$ & $\begin{array}{l}\text { Measures of } \\
\text { enhanced } \\
\text { development status } \\
\text { when benefits are } \\
\text { realised, quantified } \\
\text { and time bound }\end{array}$ & $\begin{array}{l}\text { Base line and ex-post } \\
\text { surveys, direct } \\
\text { observation or } \\
\text { secondary data, reports }\end{array}$ & $\begin{array}{l}\text { Usually non-project } \\
\text { support factors } \\
\text { required to ensure } \\
\text { contribution to goal }\end{array}$ \\
\hline $\begin{array}{l}\text { Output } \\
\text { Specific non- } \\
\text { quantified results } \\
\text { from managed } \\
\text { activities - the } \\
\text { deliverables }\end{array}$ & $\begin{array}{l}\text { Results of managed } \\
\text { applications of } \\
\text { inputs, quantified in } \\
\text { magnitude and } \\
\text { time - project } \\
\text { management } \\
\text { indicators }\end{array}$ & $\begin{array}{l}\text { Direct observation of } \\
\text { key process and } \\
\text { implementation } \\
\text { progress indicators }\end{array}$ & $\begin{array}{l}\text { Condition for success, } \\
\text { usually within control } \\
\text { of project } \\
\text { management, required } \\
\text { to achieve purpose }\end{array}$ \\
\hline $\begin{array}{l}\text { Activities } \\
\text { Components to } \\
\text { generate the } \\
\text { outputs }\end{array}$ & $\begin{array}{l}\text { Quantified factors of } \\
\text { production required } \\
\text { to produce the } \\
\text { output via activities }\end{array}$ & Project documents & $\begin{array}{l}\text { Preproject status and } \\
\text { inputs availability }\end{array}$ \\
\hline
\end{tabular}




\section{University Library}

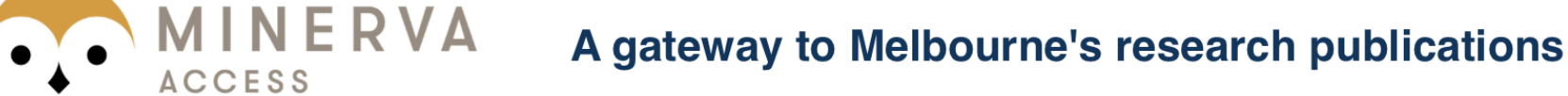

Minerva Access is the Institutional Repository of The University of Melbourne

Author/s:

Dey, PK;Hariharan, S;Ho, W

Title:

Managing healthcare technology in quality management framework

Date:

2007-01-01

Citation:

Dey, P. K., Hariharan, S. \& Ho, W. (2007). Managing healthcare technology in quality management framework. INTERNATIONAL JOURNAL OF TECHNOLOGY MANAGEMENT, 40 (1-3), pp.45-68. https://doi.org/10.1504/IJTM.2007.013526.

Persistent Link:

http://hdl.handle.net/11343/118690 